\title{
Editorial:
}

\section{Public Policy Responses in a Time of Pandemic}

\section{Cheryl N. Mohamed Sayeed ORCID iD: https://orcid.org/0000-0002-9548-1139}

Understanding Public Policy requires an analysis of the legislation, programmes, and policy guidelines, which are set up by governments to respond to the socio-economic and political needs of society, and the impact of the policies themselves. Most public policies are aimed at guiding the delivery of public goods and services. However, some policies are designed to bring about change, whilst others seek to respond to change. Public policy is an expression of the commitment (political will), or lack thereof, on the part of a government to act on issues that affect society. The effectiveness of the public policy, can be best evaluated through an examination of the governance mechanisms adopted to achieve policy implementation, and the change brought about as a result of the policy. Here, governance refers to the strategies adopted to employ the laws, whilst balancing elements of monitoring, evaluation, accountability, inclusiveness and equity, among others. The effect of the changes, framed by the public policy, is generally the result of government formulating relevant guiding principles for public administration to carry out the policy agenda. The policy agenda outlines who gets what and how, and serves as the interface between the political will and administrative functions of government. Research into Public Policy, requires an understanding of the processes which guide the formation, implementation, monitoring \& evaluation, and impact of policies, in response to issues that affect citizens, as the policies are indicative statements of what a government intends to do, and an absence of public policy would suggest the lack of political will to act in that area (Anderson 2011; Birkland 2011; Dye 2013; Dye 1972; Lasswell 2018). The declaration of COVID-19 as a pandemic is one such issue which, unlike other steady issues presented a crises situation, and 


\section{Cheryl N. Mohamed Sayeed}

required quick action on the part of political leadership, and their government machinery, globally.

The South China Morning Post reported that the earliest reported case of corona virus can be traced back to the case of a 55-year-old male in Hubei Province on 17 November 2019 (South China Morning Post 2020). The earliest cluster of infections was reported when the WHO China Country Office was notified on 31 December 2019. The infection was identified as a novel coronavirus (nCoV) on 7 January 2020. On the 13 January 2020, the first COVID-19 cases outside China were reported, and by 30 January 2020, the WHO declared a public health emergency. What unfolded in the months that followed has been very similar to the scenario 'predicted' by the now famous Ted Talk by Bill Gates in 2015 (Gates 2015), where he spoke about the next war, where missiles would be replaced by microbes, and where governments would be forced to make public policy responses in order to save lives and protect their health systems from collapsing. Similarly, the now famous Hollywood movie Contagion, released in 2011, mapped out the spread of a respiratory viral infection, which originated in a market in China and, subsequently resulted in the death of a large percentage of the global population, until a vaccine was found.

The WHO declared COVID-19 a pandemic on 11 March 2020. It is important to note that the declaration of a pandemic by the WHO requires governments to act. This arises out of the logic of the relationship between governments and citizens, where government is mandated to act, in what is deemed to be the best interest of its citizens. Such actions are described and defined in the shape and form of public policies that unfold. The declaration of a pandemic prompted public policy responses across the globe, to save lives, save the economy and protect health care systems, through various measures including rules for social distancing, lockdown of entire countries, and economic recovery measures, among other measures. Suddenly, it seemed that the doomsday scenario presented by Bill Gates in 2015, might become a reality. The fear and uncertainty that manifested from these sudden changes to people's lives created anxiety and fear. Pictures of the Spanish Flu began resurfacing to make people aware of what happened the last time a respiratory viral infection swept through the globe. There are a few important points to draw from the experience of the Spanish Flu. Firstly, 50 million people died, there was an ongoing war, and there were three waves of infection, with the second the deadliest. The book Pale Rider, written by Laura Spinney, 
published in 2017, provides a narrative history, which traces how the Spanish flu travelled across the globe, and in the process exposed the vulnerabilities of humans, whilst they were simultaneously experiencing a world war. The book is significant in framing our understanding of pandemics and the role of government, because it traced the extent to which government functionality and family relations became disrupted, whilst as the same time, created opportunity for innovation in various areas, most notably in medicine. The book further traces the simultaneous major shifts in the way in which, not only people and communities considered their positions in the world, but made government rethink their local and global positioning. The pandemic of 1918, Spinney (2017) argues, was partly responsible for pushing India to independence, South Africa to apartheid, and Switzerland to the brink of civil war. It also created what she describes as a 'lost generation' due to the socio, economic, and political challenges that this period witnessed. Based upon the descriptions by Spinney (2017), the element of mental health was an additional dilemma, due to the dual impact of flu on the brain, combined with the socio-economic trauma that unfolded. This is currently proving to be an important dimension for investigation during COVID-19 as the impact of lockdown takes effect.

It is important to draw attention here to the logic and impact of lockdown. The fundamental rationale arises out of the need to keep people away from each other, and based upon mathematical models, keep rates of infections down, which in turn can ease the burden on health care systems. Mikes and Power (2020) have argued that,

In many ways, lockdown is intellectually easy. It is unpleasant, economically damaging and hard to police. But as a remedy it is clearcut. The exit strategy is much less clear .... In the case of COVID-19, we expect that the process of transition will be lengthy but not smooth. Yet, we have little to guide us.

This is very much the scenario which has played itself out in South Africa. The passing of laws and regulations to impede movement was backed by political will and easy to pass. However, enforcement of these rules has proved to be problematic, as it extends greater powers to the police, and in the case of South Africa, the National Defence Force, whose language and actions have told us that they are at war with citizens. This brings out a contradictory character in the policy decision making process, because the policy demands during times 


\section{Cheryl N. Mohamed Sayeed}

of turbulence, like COVID-19, requires decisions at the central level to be made immediately, whilst, the logic of being effective requires more decentralized, local level decision making. This has the potential to create conflict between what is the best practice from the view of national government, but may not necessarily be the best approach for individuals and households at the community level. The conferment of additional powers to the police and the South African Defence Force, are clear examples. In the case of the police service, who became responsible for the enforcement of new guidelines, which in some cases they did not quite understand, needed to be balanced with the realities that social distancing was impossible for many people, due to the nature of their socio-economic positions. The Defence Force, who have been in training for years with very little, if not no opportunity for deployment, were suddenly given powers over citizens. The death of Collins Khoza, at the hands of the Defence Force, is an example of what can go wrong when the contradiction in policy, creates a platform for the extension of powers for those who are not capable, and results in conflict between the intention of the policy, the realities, and policy implementation.

Perhaps the position by Hart (1961) is relevant here, where he notes that authority in any structure, like a legal system, is built on the basis that those functioning within the system understand the rules, accept the rules, and measure their conduct based upon the rules. Within the USA, the world watched the death of George Floyd at the hands of a police officer, and brought to the surface racial inequality and injustice by law enforcement, whilst simultaneously going through a pandemic. The world joined in calls for such abuse of power in all areas of all our lives to end. Hart's (1961) notion of authority is a key element for effective policy implementation and is complimentary to modern ideas of good governance, where elements of accountability, monitoring and evaluation, whilst operating within the legal framework are normative. It suggests a more persuasive form of public policy, where authority conferred is balanced with a negotiated agenda, and where there is balance between the needs and rights of the individual and community, with policies in themselves. In this regard, it is important to note that the rationale of the policy decisions around the pandemic are based on the logic of saving lives, saving the economy and the health care system. One would assume that citizens want this protection, that they support the strategies by government, and that those appointed in public office will facilitate the will of the people and government. However, the experiences of citizens at the hands 
of law enforcement, the intersection of the pandemic and race in the USA, and citizens public challenges to the pandemic regulations in Germany, Italy and the USA, are indicative that not all citizens want government to make decisions which restrict their civil rights to associate. These experiences are important and they suggest that policy decisions need to be flexible enough to accommodate the multiple experiences and circumstances of citizens, and in doing so, the power of public officials over citizens needs to be balanced with these multiple realities, especially where fast-tracked policy decision making has taken place, which does not allow for a negotiated setting of agenda.

When the pandemic began we all tried to create and experience a new normal, to work, educate, and maintain personal relationships. COVID-19 has challenged the work that we do and forced organisations to rethink how they function. The circumstances which unfolded has forced the world to adopt digital mechanisms for communication and work, a process which had begun before the pandemic, but through the pandemic, individuals and organisations previously resistant to change, have been forced to adapt quickly, albeit at a huge cost. The growth of platforms like Zoom and Google Meets is indicative of this. The pandemic has forced us to question fundamental ideas about community, in terms of what is community and how do we relate to each other. The International Labour Organisation has predicted that an estimated 1.6 Billion people have suffered severe damage to their capacity to earn a living, with a large portion of these being informal workers (ILO 2020). The pandemic has required that those in leadership positions make effective decisions quickly, whilst being flexible, in order to manage people in a time of crises. Organisational and political leadership have needed to lead, to help prevent chaos, prevent panic, and to combat the development of the 'us and them' scenario, by forging a logic that we are all in this together. As we move through this pandemic, we have changed and we adapted to new ways of doing things. Change is no longer inevitable, it is happening now. As a result, it is important for policy makers to consider ways and means by which the evolving public policy agendas can assist with documenting the narrative of the pandemic and towards developing the post COVID-19 narrative.

Globally there have been varying public policy responses to COVID19 offering useful case studies. From control in China, the quest for herd immunity in Sweden, controversy in Brazil, and to the effects of non-decision making evident from the case of the United States of America, under current President Trump, every country has a story. This is all within the overarching 


\section{Cheryl N. Mohamed Sayeed}

aim by governments to find a viable vaccine, for their citizens. While scientists focus on finding this vaccine, and governments commit resources towards this, it is important to consider the emerging counter narratives, where the loudest voice in this regard is perhaps Vandana Shiva. In her most recent book, Oneness vs. the 1\%: Shattering Illusions, Seeding Freedom, in true Shiva style, she questions the involvement of the $1 \%$ population of Zuckerberg, Gates and others in the matters of health, digital monitoring and food production, and the kinds of investment into vaccines currently being witnessed, and coins this involvement as 'a new colonialism', one which colonises the mind!

For public policy makers, the pandemic has been the biggest test, requiring quick action and decision making to combat and curb the spread of the virus. As a health care crisis, with potential economic collapse, and the disruption of our social lives, COVID-19 has required unprecedented global action by public policy makers. For the Policy Sciences, COVID-19 requires understanding of the policy dynamics, and how these have shaped and influenced citizens, organisations and government, in their attempt to respond to the spread of the virus. This special edition of Alternation seeks to highlight some of the key Public Policy issues which have shaped and impacted on the South African government's responses to COVID-19. It must be noted that at the time of writing this editorial, a second wave of infections is sweeping through Europe, bringing on a renewal of restrictions on movement and the reintroduction of lockdowns, which have already proved to be damaging not only to the mental health of communities, but the economic welfare and capabilities of people. Perhaps, the time since March, and the experiences gained and lessons learned from the first wave have been sufficient for those who occupy public office to make better decisions, and that the next round of public policies are effective, efficient and void of corruption. But then again, we live in a country where corruption has become endemic to the way in which government governs.

The pandemic has definitely brought about 'a fundamental shift' in our way of life, as described by President Ramaphosa, in his address to the nation on 15 March 2020. As we traverse this new terrain, and we are hopeful for the post COVID-19 narrative, academics, researchers, and practitioners, in all areas of life need to begin asking critical questions, including: How do we hold the state accountable for decisions made during a pandemic? What will the effects of COVID-19 be on state authority? To what extent will the experience of the pandemic help to expedite strategies to reduce social inequality? How 
can we design and implement projects that are flexible, and which respond and adapt to changing institutional arrangements? What are the effects and impacts in the existing socially-fractured nature of South Africa, with regard to matters of race and gender, post COVID-19? What potential is there for change in our public service? How do we measure a successful social contract post COVID19? Has the role of public trust in determining good governance changed? What mechanisms are necessary to enable government to respond to change more readily and successfully to pandemics in the future? Can the public policy redistribution function be balanced with regeneration? What information is needed in order to help rebuild? How do we prevent the next pandemic? How can we better prepare for the next pandemic? What are some of the main sociocultural changes government has to consider, with regard to post-COVID-19 public policy development?

This special edition highlights some of the key policy issues that must be considered in considering current COVID-19 response strategies in the context of pre-COVID-19 capabilities, and the challenges arising out of the pandemic. The edition thus presents peer reviewed articles which seek to place a spotlight on recently completed research and policy considerations, which consider their findings and conclusions within the context of the current public policy conundrums, presented by COVID-19. The articles received reflected on the myriad of public policy challenges and opportunities which have unfolded since the declaration of a pandemic, and in true Public Policy style, the edition brings together contributions from academics, practitioners, and Supervisors with their PhD Candidates.

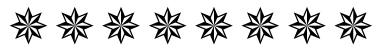

The edition begins with the article by Felicia Clement and Alan Whiteside who in 'Lessons from the Comparison of Age Composition and Concomitant Mortality Profiles of COVID-19 Patients in Selected Developed and Developing Countries', provide an examination and analysis of COVID-19 data in order to identify reasons for the variation between developed and developing countries. The article is useful for understanding the policy context of COVID-19, because it draws out the stark realities of the pandemic in terms of infection rates, and reflects on the capacity of governments to respond. The analysis which focuses on the age profiles of populations in selected countries, 


\section{Cheryl N. Mohamed Sayeed}

seeks to draw out the policy implications of this variation. The analysis reveals that high SDI countries can afford to support their populations for a time, whilst the situation in low SDI countries is bleak, as they have to cope with increased poverty, hunger and other diseases for many years. The article further highlights that the short-term policy impacts must be further investigated in order to ensure impactful public policies, because until there is a vaccine, effective public policies will play a pivotal role in containing the virus.

Policy responses in any environment are driven by the main approach adopted by government to respond to crises. Evidence-based policy making is increasingly being used as the mechanism for effective decision making in governments across the globe. In 'COVID-19 and Evidence-based Policy Making: A Case Study of Water and Sanitation in South Africa', Sibusiso Xaba and Cheryl N. Mohamed Sayeed, a PhD Candidate and Supervisor team, examine the extent to which evidence-based policy making informs decision making within the water and sanitation sector of South Africa, through a case study of eThekwini Municipality. In achieving this, the article, begins with a discussion of evidence-based policy making, and then reflects on some of the findings of the empirical investigation, undertaken by the $\mathrm{PhD}$ Candidate, by way of a mixed methodology approach. The article emphasizes that COVID-19 has brought to the fore the critical challenges regarding water access and that whilst the eThekwini municipality has been quick to respond through the use of available evidence, to the challenges related to access to water during COVID-19, the sustained ability to use the approach is limited by the capacity of policy decision makers to use available evidence.

As part of the COVID-19 response, governments and institutions alike have been forced to adopt digital platforms to not only function effectively, but to ensure continued survival. At the level of government, a key part of monitoring and evaluation of strategies adopted to curb the spread of the virus, has been to adopt an effective tracking and tracing of contacts, where positive results have been identified. In, 'Using Technology to Track-and-trace in the COVID-19 Era: An Analysis of South Africa's Legal Framework', Lee Swales outlines the legal framework for the adoption of a digital track and trace system within South Africa. Swales contribution further comments on the interaction between the Protection of Personal Information Act 4 of 2013 ('POPIA') and the COVID-19 Tracing Database, in so far as they impact on the freedoms of individuals. This discussion further examines the legal boundaries related to the rationality of some of the lockdown measures adopted to curb the spread 
of the virus. The article demonstrates that this database is not the ultimate solution, and it must be read together with other measures, whilst at the same time, balance the purpose together with the objective of the database.

In, 'Dissecting Disaster Response during COVID-19: An eThekwini Municipality Experience', Evangelos A. Mantzaris and Bethuel Ngcamu dissect the existing prevention, preparedness, and mitigating response and recovery strategies in minimizing the impacts of COVID-19 to the vulnerable communities of eThekwini Municipality, and to analyse the effectiveness of municipal enforcement agencies, operations, institutional arrangements and governance, as well as the efficiency of the response plans to the pandemic. The article adopts an ethnographic participant observation approach in order to reflect on the researchers' experiences, the realities of vulnerable groups living in informal settlements in eThekwini, combined with their susceptibility to the COVID-19 pandemic. In so doing, the article reflects on a qualitative case study, analysed through content analysis. The article reflects that the eThekwini Municipality Disaster Management Centre does not comply with particular crucial sections of the Disaster Management Act and cannot 'effectively, efficiently and proactively, prevent, mitigate and respond to the coronavirus and its effects'. This is based upon the shortage of qualified staff capable of achieving the objectives of the centre, which impacts on their functionality and inability to effectively co-ordinate. The article suggests that it is necessary for the Provincial government to intervene and that suitably qualified and capable individuals be employed in order to lead disaster management in the municipality.

Desiree P. Manicom and Erna Kruger reflect on the impact of the hard lockdown on small scale farmers in 'The Impact of COVID-19 'Hard' Lockdown Disaster Management Regulations on Small-scale Farmers: The Case of Central and Southern KZN Small-scale Farmers Employing Climate Resilient Agriculture Production'. The article reflects on the data from a qualitative structured survey that was conducted with small-scale farmers in a climate resilient agriculture (CRA) programme, which is run by Mahlathini Development Foundation (MDF). The article shows that the COVID-19 lockdown had a negative impact on the ability of poor rural households to survive. The article further highlights the role played by the police in enforcing the social distancing rules, and that the enforcement of these rules impeded on ability of poor households to maintain their and their community's food supply. The article reflects the contradiction in the policy design and decision making 
process which was undertaken in developing and enforcing the Disaster Management regulations.

Ian A. Nzimakwe and Nokuthula N. Jili in 'Policy Responses to the COVID-19 Crisis: Depending on Local Governments for Long-Term Stability' explore the role of policy in a crisis. The article emphasizes that local government is a critical element of informing local governance due to its proximity to communities. This policy role of local government is further examined by Purshottama Reddy and Ajiv Maharaj in 'Local Government's Economic Response to COVID-19: The Case of eThekwini City Council in Durban, South Africa'. This article reflects on both the findings of an online business survey conducted by eThekwini Municipality, and on the municipal response in developing an economic recovery plan, to consider the role of local government in economic support and recovery. The findings mapped the COVID-19 provisions from a national and local level, and in so doing, the eThekwini Plan for recovery is presented. These articles contribute to the body of knowledge regarding COVID-19 impact and responses for local government.

The second PhD Candidate in this edition, John Modise together with his supervisors Derek Taylor and Kishore Raga present the article 'Service Delivery from a South African Police Service Perspective'. The article reflects on the findings of a recently completed $\mathrm{PhD}$ study, which aimed to investigate the expectations and perceptions of members of the public towards the South African Police Service (SAPS); as well as service delivery in the Community Service Centre (CSC) in the Kimberley Cluster, and to consider the implications of COVID-19 in this regard. The article reflects on the findings of a survey of one hundred respondents whose responses were analysed using Descriptive and Inferential statistics, with the five service quality dimensions of the Servqual Model, being the measure of the client's expectations and perceptions. The results revealed that in all five service quality dimensions: (tangibility, reliability, responsiveness, assurance and empathy); that there was a negative quality gap, and that there are significant differences between perception and expectations of the clients in all five service quality dimensions. The article calls for a need to improve all areas of service quality, and recommends the use of a conceptual model to explain the relationship between customer satisfaction and services delivered by the SAPS more extensively.

Evangelos A. Mantzaris and Pregala Pillay present the article 'COVID-19, Health Systems Corruption, Economic Priorities and Poverty: 
The Case of South Africa', wherein they examine the intersection of the wide range of issues (sociological - criminological - historical) related to social policy issues, and the emerging 'responsibilities, capabilities and relationships of state layers and institutions, and the measures undertaken' to combat COVID-19. The article highlights, that while South Africa was progressive in its policy direction in the initial stages of the pandemic, the emerging consequences of 'chronic corruption at all levels and sectors', had negative consequences for the poorest communities. The article provides an important contribution as it shows that despite well-meaning policies, corruption continues to be a major stumbling block in the provision of services in South Africa, even during a pandemic.

Zwelinzima Ndevu in 'Understanding the effects of COVID-19 on Universities in South Africa: An Evidence Based Approach', the impact of COVID-19 on higher education is highlighted through reflection on the experiences of academic staff from a selection of institutions of higher learning. The article adopts a qualitative, interpretative empirical frame, and uses content analysis of primary and secondary sources, and six interviews with purposely selected academics from three universities in South Africa. The interviewees identified critical concerns which must be considered as they reflect problems faced by the students and academics at all levels, resultant from the adoption of online learning at the onset of the pandemic. The analysis is informed by the logic of evidence-based policy making. As part of the COVID-19 response, it has been critical for institutions of higher learning to find ways of adapting to the move to on line learning. Various challenges have been experienced partly due to access to devices and access to data, among other issues.

Fazlun Peterson, in 'Towards Student Inclusivity during COVID-19: Testing the \#datafree Moya Messenger', reflects on the findings of a case study which piloted the \#datafree Moya Messenger application. This is a zero-rated app, was designed for use by students of the University of Western Cape, to engage with online learning through the iKamva e-learning management system, as it was found that not all network providers had zero-rated the University website. Some of the findings highlighted in the article, include, that there were challenges in the initial implementation of the application, the app itself required the use of mobile data or $\mathrm{WiFi}$, and the application was not available to iPhone users. The introduction of this app is innovative in its approach, and will allow students access to teaching material, and has the 


\section{Cheryl N. Mohamed Sayeed}

potential to enable students to participate in assessments, even if they have no available data. The article is a useful resource for all those engaging with on line learning, as it reflects that students, when offered reasonable equitable access to learning platforms, can participate, and that the accessible platform can help to address some of the challenges in terms of access and experience in different circumstances, as outlined in the preceding article by Ndevu. It is envisaged that there will be a second phase of this study to examine students' perceptions about the application itself, which can assist with making more informed decisions about the best methods and mechanisms for communicating with students at institutions of higher learning. These experiences at UWC, could no doubt be replicated at other institutions.

Kunle Oparinde and Vaneshree Govender in 'Disruptions from COVID-19: Challenges and Opportunities for Research Outputs in South African Higher Education', contribute to the discussions by Ndevu, and Petersen by considering the challenges and opportunities for academics, specifically in regards to knowledge production and productivity. In so doing, they identify several mechanisms for research opportunities arising out of the situation presented by COVID-19, which researchers and key stakeholders might need to consider.

These reflections by Ndevu, Petersen and Oparinde \& Govender, of the experiences of academics and students, and the challenges and opportunities for research respectively, open the debate for critical policy issues in higher education, which Ashwin Desai in his article 'The Digital University: Of March Hares and Tortoises' does. Desai is provocative in his discussion, which raises awareness of the multi-layered reality of the learning environment of universities with the onset of COVID-19. Desai, in his examination of the experiences of lecturers, who have been challenged to teach online, asks key questions about the implications for disciplinary boundaries and knowledge production in academia during COVID-19. Desai critically examines the challenges to the 'traditional notions of the role of universities and the changing orientations of the academy against the backdrop of the global juggernaut of privatised higher education'. His imagery using the world of Aesops Fables, provides an extraordinary analysis of the 'wicked problems', arising out of the policy responses which unfolded with the declaration of a pandemic, and contextualises these. In reading the article, one quite easily imagines the logic of slow and steady, an approach promoted widely the $1980 \mathrm{~s}$ as a viable public policy approach for successful, impactful change. Further, 
that slow and steady might take one into the unknown, where sometimes little progress can be seen, and eventually seeing the end, and finding more value and improved ways of doing, thinking and being. Even more so, Desai raises critical questions about research and knowledge within academia, which must be given consideration when we emerge out of this pandemic, as these questions have direct policy relevance, and undoubtably can have impact on the shape, form and quality of academia beyond COVID-19.

\section{References}

Anderson, J.E. 2011. Public Policymaking: An Introduction. $7^{\text {th }}$ Edition. Wadsworth: Texas A\&M University.

Birkland, T.A. 2011. An Introduction to Policy Process: Theories, Concepts and Models of Public Policy Making. $3^{\text {rd }}$ Edition. New York: ME Sharpe. De Coning, C. \& F. Cloete (eds.). 2006. Improving Public Policy: Theory, Practice and Results. $3^{\text {rd }}$ Edition. Pretoria: Van Schaik publishers.

Dye, T. R. 2013. Understanding Public Policy. New Jersey: Pearson Prentice Hall.

Dye, T.R. 1972. Understanding Public Policy. New Jersey: Prentice-Hall, Gates, B. 2015. Bill Gates: The Next Outbreak? We're not Ready - TED Talks. Available at:

https://www.ted.com/talks/bill_gates_the_next_outbreak_we_re_not_rea dy?language $=$ en $($ Accessed on 15 March 2020).

Lasswell, H.D. 2018. Politics: Who Gets What, When and How? USA: Papamoa Press.

Peters, B.G. 2015. Advanced Introduction to Public Policy. New York: Edward Elgar.

Shiva, V. 2020. Oneness vs. the 1\%: Shattering Illusions, Seeding Freedom. USA: Chelsea Green Publishing.

Hart, H.L. 1961. The Concept of Law. Oxford: Oxford University Press.

Howlett, M. 2019. The Policy Design Primer: Choosing the Right Tools for the Job. London: Routledge.

https://doi.org/10.4324/9780429401046

Howlett, M. \& M. Ramesh. 2003. Studying Public Policy: Policy Cycle and Policy Subsystems. $2^{\text {nd }}$ Edition. Canada: Oxford University Press.

International Labour Organisation (ILO) 2020. As Job Losses Escalate, Nearly 
Half of Global Workforce at Risk of Losing Livelihoods. Available at: https://www.ilo.org/global/about-theilo/newsroom/news/WCMS 743036/lang--en/index.htm (Accessed on 05 May 2020).

Mikes, A. \& M. Power 2020. The Switch: Negotiating between Normality and Crisis. Available at: https://www.sbs.ox.ac.uk/oxford-answers/switchnegotiating-between-normality-and-crisis (Accessed on 12 May 2020). Spinney, L. 2017. Pale Rider: The Spanish Flu of 1918 and How it Changed the World. New York: Johnathon Cape Publishers.

Peters B.G. 2015. An Advanced Introduction to Public Policy. Cheltenham: Edward Elgar.

South Morning Post 2020. Coronavirus: China's first Confirmed Covid-19 Case Traced Back to November 17. Available at: https://www.scmp.com/news/china/society/article/3074991/coronaviruschinas-first-confirmed-covid-19-case-traced-back (Accessed on 4 June 2020).

Cheryl Mohamed Sayeed Public Policy University of KwaZulu-Natal Howard College (Durban) Mohamed-Sayeedc@ukzn.ac.za 